\title{
Is diabetes self-management education still the Cinderella of diabetes care?
}

\author{
Lorna Hurley $^{1}$, Máire O'Donnell ${ }^{2}$, Mary Clare O'Hara ${ }^{1}$, Marian E. Carey ${ }^{3}$, Ingrid Willaing ${ }^{4}$, \\ Heather Daly ${ }^{3}$, Seán F. Dinneen ${ }^{1,2}$ \\ ${ }^{1}$ Centre for Diabetes, Endocrinology and Metabolism, University Hospital Galway, Ireland \\ ${ }^{2}$ Discipline of Medicine, National University of Ireland Galway, Ireland \\ ${ }^{3}$ Leicester Diabetes Centre, University Hospitals of Leicester NHS Trust, Leicester, UK \\ ${ }^{4}$ Diabetes Management Research, Steno Diabetes Center, Gentofte, Denmark
}

\section{Corresponding author at:}

Lorna Hurley, Centre for Diabetes, Endocrinology and Metabolism, University Hospital Galway, Ireland.

Phone: +353 91 542713; E-mail: Lorna.Hurley@hse.ie 


\section{Abstract}

This paper reflects on the status of diabetes self-management education (DSME) as a branch of diabetology in Europe and discusses some opportunities for better supporting DSME delivery. DSME (also commonly known as Therapeutic Patient Education) has been evolving as a therapy for diabetes for decades. As a continent, Europe is fortunate to have nurtured many pioneers in DSME, and currently has many experts in the field progressing the knowledge base and striving to improve access to DSME for people with diabetes. While there is a wide variety of DSME programmes being delivered throughout Europe, for most people diabetes education is not truly embedded in routine clinical care, being seen as more of an optional add-on to conventional therapies. In comparison to drugs and devices, DSME lacks investment, and funding for DSME research lags far behind other therapies. The rigour with which forms of DSME are developed and evaluated varies, and there is a lack of European quality standards. To try to address some of these deficiencies, greater pan-European collaboration and leadership is required.

\section{Introduction}

In 1979, at the inaugural meeting of the Diabetes Education Study Group (DESG) in Geneva a Belgian physician, Dr. Jean Pirart, delivered a talk entitled "Why is education still the Cinderella of diabetology?" According to Wikipedia the word Cinderella has come to mean "one whose attributes are unrecognized, or one who unexpectedly achieves recognition or success after a period of obscurity and neglect" (https://en.wiktionary.org/wiki/Cinderella). In this paper, we will consider whether diabetes self-management education (DSME) has received the recognition it deserves as a therapy for diabetes or whether it remains a neglected therapeutic area.

Management of a chronic condition requires a paradigm shift away from the traditional doctor-led model of diagnosis and treatment to a collaborative model where the person with diabetes and their 
healthcare professional work together in partnership towards achieving agreed optimal long-term outcomes. Joint position statements from the European Association for the Study of Diabetes (EASD) and the American Diabetes Association (ADA) promote a person-centered approach to diabetes management (1) (2). Patient-centered care is defined as an approach to "providing care that is respectful of and responsive to individual patient preferences, needs, and values and ensuring that patient values guide all clinical decisions" (3) Self-management support strategies, defined as "activities that assist the person with diabetes in implementing and sustaining the behaviors needed to manage his or her condition" are essential to this new collaborative model (4). DSME is one such support strategy, has a strong evidence base, and aims to "support informed decision making, self-care behaviors, problem solving, and active collaboration with the health care team, and to improve clinical outcomes, health status, and quality of life" (4). In the following paragraphs, we will 1) discuss the current state of DSME delivery in Europe 2) discuss the state of research in the area of DSME, 3) reflect on the state of DSME as a branch of diabetology in Europe almost 4 decades after Dr. Pirart delivered his talk with the thought-provoking title, and 4) consider future developments in DSME.

\section{The current state of DSME delivery in Europe}

Despite a policy shift towards patient-centered self-management of diabetes (5), access to DSME has been described as being like a "lottery" in most European countries, depending very much on where people receive their diabetes care (6). A compendium of DSME programmes in Europe highlights the variety of types and formats of diabetes patient education currently available (7). These include validated diabetes education programmes, a wide variety of locally developed programmes, topic-specific education sessions on issues such as insulin therapy, physical activity, carbohydrate counting and foot care. Education is being delivered in groups, on an individual (or family) basis, by telephone or mobile technology, by professionals, lay health workers and peers. The sheer number and variety of programme types and modes of delivery raises the issue of definition, quality and standards. There is a danger that any education programme is seen to be of equal quality to the next by decision-makers, resulting in decisions on what programmes are delivered being swayed primarily by cost. 
Few European countries have agreed national standards for DSME and there seems to be varying interpretations of the term 'diabetes self-management education' (7). For this reason, cross-region and cross-country comparisons of DSME, such as those in the IDF global diabetes scorecard, are of little meaning (8). Without a clear benchmark, we can delude ourselves into thinking we are doing a good job while we may not in fact be doing so at all. Standards are designed to define quality DSME and support, and to assist clinicians and educators in providing evidence-based education. As there are many good models for the provision of diabetes education, standards do not endorse any one approach, but rather seek to delineate the commonalities among effective and excellent self-management education strategies (4). There is a need for European-experts to collaborate to agree definitions and quality standards, as has been done in the United States, so that all European citizens with diabetes have access to high quality education (4).

\section{The state of DSME research in Europe}

Following the pioneering work of Jean-Phillipe Assal and Michael Berger, researchers and clinicians throughout Europe have made significant contributions to the evidence for DSME being an important element of effective diabetes care. Trials of interventions such as the Insulin Treatment and Teaching Programme (ITTP) in Germany, Austria and Romania, the DAFNE trials in the UK and Ireland, the DESMOND and X-PERT research programmes in the UK, and the ROMEO trials of pedagogical group medical care in Italy, are influencing the policy and practice of diabetes care in Europe (9) (10) (11) (12) (13). Proof of efficacy for DSME has been demonstrated with several systematic reviews synthesizing the evidence (14) (15) (16) (17).

Funding for DSME research in Europe can be difficult to secure. For example, the European Foundation for the Study of Diabetes (EFSD) funds joint initiatives supported by pharmaceutical companies but the vast majority of funding goes to basic and clinical science research. Of 116 awards made in 2014 and 2015, only two were related to diabetes self-management education. Less than $0.5 \%$ (4/1226) of abstracts presented at the European Association for the Study of Diabetes (EASD) 2016 annual congress focus on the area of self-management education. This is just an example of the challenging environment in which DSME finds itself. It is an unfortunate 
reality that the medical research agenda is increasingly being set by the drug and medical device industries with patient-centered outcomes research being given less emphasis (18).

There are a number of forums in Europe for researchers with an interest in DSME to network, share research findings and create opportunities for collaboration. Within the EASD, various study groups tend to bring together researchers with an interest in a specific area of diabetes care or science, with the Diabetes Education Study Group (DESG) representing those interested in DSME. Recently the Diabetes Self-Management Alliance (www.diabetesalliance.org.uk) has been established with the goal of improving access to, and the quality of, structured education. It would make sense for these groups to collaborate, bringing together researchers and clinicians, with the aim of addressing priority issues such as defining European quality standards for DSME.

\section{Why is DSME not considered an important branch of diabetology?}

Although DSME has been shown to be cost-effective, it doesn't receive the same investment, promotion and marketing as drugs and devices (which are associated with financial gain). Despite proven efficacy some doctors are still not convinced that DSME is appropriate for their patients, doubt whether it will result in better outcomes, and question its evaluation (19). One could argue that the beliefs and attitudes of medical professionals may be affecting their perception of behavioural interventions. The tendency in medicine to emphasize quantifiable biomedical outcomes (such as standard metrics related to survival and physiological outcomes) over patientoriented outcomes (outcomes that are important to patients such as quality of life) begins in medical school (20) (21). However, patient education does not lend itself well to reductionist science. It is a complex intervention requiring both quantitative and qualitative methodologies drawn from multiple disciplines, consideration of patient-oriented and psycho-social outcomes, as well as the traditional biomedical outcomes.

While there has been a focused shift away from the traditional medical models of practice where the clinician is perceived as the expert who holds a position of authority over the patient, some clinicians still struggle with the shift to shared control. Part of this tension may be associated 
with the complexity of balancing protective aspects of care (e.g. ensuring patients avoid harmful consequences) with elements of patient choice and responsibility (22). This links to the

clinicians' tendency towards self-blame, assuming responsibility when their diabetes patients do not achieve targets (23). These clinicians are likely to wrestle with the concept of self-management education which, by its nature, aims to empower patients to take control over their condition and hence diminish the control of the health care professional. However, diabetes selfmanagement is a complex process that is dependent on much more than the actions, attitudes or beliefs of health care professionals. It is also influenced by individual patient characteristics, their environment, the presence or absence of supportive relationships, the health care system, cultural factors as well as the prevailing economic conditions in their country (24). Further research is required to understand how these influencing factors, including the role of health care professionals, affect diabetes self-management.

Embedding self-management support strategies such as DSME into practice is a 'process'. As well as committed resources, it requires management support and diabetes team support. Leadership and 'change champions' are two critical factors affecting its success (25). Leaders influence policy, secure resources, set an example and share a clear vision. 'Change champions' move programmes through the phases of development to implementation. They mentor staff and actively demonstrate and role model what patient self-management education looks like. Transformational change around DSME cannot occur without the active support of the most powerful people in a healthcare organisation to guide and drive change and support others to also lead. It is clear that we need stronger champions of DSME in diabetology. The challenge however is to identify and develop these champions and create an infrastructure within which they can gain support, motivation, ideas and strength in numbers. The DESG and Diabetes Self-Management Alliance can play an important role in this process.

\section{What might the future look like?}

Current research suggests a number of new focus areas for DSME development, including strategies to improve uptake of education, validating more flexible and ongoing approaches to 
DSME, optimizing the benefit of devices through DSME and the vast domain of mobile and online health technology (m-health).

Until recently, research in DSME has primarily focused on proof of efficacy. However, it has now become clear that many programmes struggle with uptake (26) (27) and researchers have started exploring barriers and facilitators of referral practices and attendance (28). With uptake levels for group-based structured education in the UK at just $0.9 \%$ (type 1 diabetes) and 3.8\% (newly diagnosed type 2 diabetes), some have called for greater patient choice of DSME, recognising that people have different educational needs at different times in their lives (27). However, the balance of flexibility (through patient-centeredness) and quality (traditionally involving structure) is a difficult one and warrants further research. What is clear however is that the field of DSME is dynamic, and new approaches are constantly evolving. Considering that learning is a lifelong process, there ought to be a place for a variety of theory-driven evidence-based approaches.

As diabetes management becomes more technical, through the use of devices such as insulin pumps, DSME can have a valuable role to play in optimising the impact of these expensive tools. For example, attendance at an education programme (covering insulin self-adjustment) is usually a prerequisite for transition to insulin pump therapy. The potential for DSME to enhance medical device benefits is just beginning to be explored (29).

M-health is constantly evolving to incorporate new advances in technology and to respond and adapt to changing health needs. Methods vary from basic information provision, to interactive sites through to virtual 3D communities which together, hold great promise as a new platform for selfmanagement. Interactive computer-based interventions for type 2 diabetes education (delivered within clinic or from home) have been shown to have a beneficial effect on blood glucose control (30). While there is an increasing array of diabetes management applications providing functions for recording medication adherence, blood glucose monitoring, lifestyle and weight, their potential for behaviour change should be further explored. Health professionals need to step into this domain and ensure that emerging applications and websites offer more than just data logging and information giving. The process of shared decision making requires that "a clinician and patient act as partners, mutually exchanging information and deliberating on options, in order to reach a 
consensus on the therapeutic course of action" (31). In this respect, health related social media platforms such as websites and applications for social networking, instant messaging, telephony etc. hold potential for facilitating shared decision making (32) Even if clinicians do not engage personally with these technologies, they should be encouraged to have greater awareness of the different resources available and guide their patients to reputable sites.

\section{Summary}

The integration of DSME in routine diabetes care is the essence of person-centered care. DSME makes the person with diabetes top-priority, embraces shared decision-making, and paves the way for strong patient-clinician relationships, which are all key elements of evidence-based medicine (21). However, in comparison to other diabetes therapies, DSME still appears to be the Cinderella of diabetology. At a European level, DSME needs governance with the development of quality standards to enable cross-country benchmarking. At national and regional level it needs clinical leadership, to ensure investment and supportive policies, and at a local level, it needs change champions to ensure that DSME is embedded in routine diabetes care. With greater collaboration, leadership and direction, Cinderella really can become the belle of the ball. 


\section{Acknowledgements}

All authors were involved in drafting, reviewing and editing the manuscript and contributing to the discussion. All authors approved the final version of the article.

\section{Funding}

This research did not receive any specific grant from funding agencies in the public, commercial, or not-for-profit.

\section{Conflicts of Interest}

SFD, MCOH, MEC, IW and HD are involved in the Diabetes Self-Management Alliance without any financial gain. There are no other potential conflicts of interest relevant to this article. 


\section{References}

[1] S.E. Inzucchi, R.M. Bergenstal, J.B. Buse, M. Diamant, E. Ferrannini, M. Nuacj, et al. Management of hyperglycemia in type 2 diabetes, 2015: a patient-centered approach: update to a position statement of the American Diabetes Association and the European Association for the Study of Diabetes. Diabetes Care 38 (2015) 140-149.

[2] S.E Inzucchi, R.M. Bergenstal, J.B. Buse, M. Diamant, E. Ferrannini, M. Nauck, et al. Management of hyperglycemia in type 2 diabetes: a patient-centered approach: position statement of the American Diabetes Association (ADA) and the European Association for the Study of Diabetes (EASD). Diabetes Care 35 (2012) 1364-1379.

[3] Committee on Quality of Health Care in America: Institute of Medicine. Crossing the Quality Chasm: A New Health System for the 21st Century. Washington, DC: The National Academies Press (2001)

[4] Haas L, Maryniuk M, Beck J, Cox CE, Duker P, Edwards L, et al. National Standards for Diabetes Self-Management Education and Support. Diabetes Care 37 (2014) S144-S153.

[5] A.A. Kousoulis, E. Patelarou, S. Shea, C. Foss, I.A. Ruud Knutsen, E. Totorova E, et al. Diabetes Self Management Arrangements in Europe: A Realist Review to Facilitate Project Implementation in Six Countries. BMC Health Serv Res 14 (2014) 453.

[6] B.A. Garrofé, A. Björnberg, A.Y. Phang, for the Health Consumer Powerhouse. Euro Diabetes Index. Health Consumer Powerhouse Limited (2014).

[7] S. Saha, G. Muller, H. Riemenschneider, P.E.H. Schwarz, for the Diabetes Literacy Consortium. Compendium of Diabetes Self Management Education Programmes in the European Member States, Israel, Taiwan and the USA. Dresden (2015).

[8] Internation Diabetes Federation. Global diabetes scorecard. Tracking progress for action. Brussels (2014).

[9] I. Mühlhauser, I. Bruckner, M. Berger, D. Cheta, V. Jörgens, C. Ionescu-Tîrgovişte, et al. Evaluation of an intensified insulin treatment and teaching program as routine management of type 1 (insulin-dependent) diabetes: the Bucharest-Dusseldorf Study. Diabetologia 30 (1987) 681-690.

[10] DAFNE Study Group. Training in flexible, internsive management to enable dietary freedom in people with type 1 diabetes. Dose Adjustment for Normal Eating (DAFNE) randomised controlled trail. Brit Med J 325 (2002) 746. 
[11] T.A. Deakin, J.E. Cade, R. Williams, D.C. Greenwood. Structured patient education: the diabetes X-PERT Programme makes a difference. Diabetic Med 23 (2006) 944-954.

[12] M. Trento, S. Gamba, L. Gentile, G. Grassi, V. Miselli, G. Morone, et al. Rethink Organization to iMprove Education and Outcomes (ROMEO): A multicenter randomized trial of lifestyle intervention by group care to manage type 2 diabetes. Diabetes Care 33 (2010) 745-747.

[13] S.F. Dinneen, M.C. O'Hara, M. Byrne, D. Smith, C.H. Courtney. C. McGurk, et al. Group follow-up compared to individual clinic visits after structured education for type 1 diabetes: a cluster randomised controlled trial. Diabetes Res Clin Pract. 100 (2013) 29-38.

[14] T. Deakin, C.E. McShane, J.E. Cade, R.D. Williams. Group based training for selfmanagement strategies in people with type 2 diabetes mellitus. Cochrane Database Syst Rev (2005) 2:CD003417.

[15] E. Loveman, G.K. Frampton, A.J. Clegg. The clinical effectiveness of diabetes education models for Type 2 diabetes: a systematic review. Health Technology Assessment. 12 (2008) 9.

[16] A. Steinsbekk, L. Rygg, M. Lisulo, M.B Rise, A. Fretheim. Group based diabetes selfmanagement education compared to routine treatment for people with type 2 diabetes mellitus. A systematic review with meta-analysis. BMC Health Serv Res. 12 (2012) 213.

[17] C.A. Chrvala, D. Sherr, R.D. Lipman. Diabetes self-management education for adults with type 2 diabetes mellitus: A systematic review of the effect on glycemic control. Patient Educ Couns 99 (2016) 926-943

[18] Patient-Centered Outcomes Research Institute. http://www.pcori.org/. (Acccessed 20171 16)

[19] P. Sunaert, M. Vanderkerckhove, H. Bastiaens, L. Feyen L, P.V. Bussche, J. De Maeseneer, et al. Why do GP's hesitate to refer diabetes patients to a self management education programme: a qualitative study. BMC Fam Pract 12 (2011) 94.

[20] H.J. Wilson. The myth of objectivity: Is medicine moving towards a social constructivist medical paradigm? Fam Pract 17 (2000) 203-209.

[21] T. Greenhalgh, J. Howick, N. Maskrey. Evidence based medicine: a movement in crisis? Brit Med J 384 (2014) g3725.

[22] S. Mudge, N. Kayes, K. McPherson. Who is in control? Clinicians' view of their role in self-management approaches: A qualitative metasynthesis. BMJ Open. 5 (2015) e007413. 
[23] E.A. Beverly, M.D. Rhtolz, K.M. Brooks, B.A. Hultgren, Y. Lee, M.J. Abrahamson, et al. A qualitative study of perceived responsibility and self-blame in type 2 diabetes: reflections of physicians and patients. J Gen Intern Med 27 (2012) 1180-1187.

[24] S. Hinder, T. Greenhalgh. "This does my head in". Ethnographic study of self management by people with diabetes. BMC Health Serv Res 12 (2012) 83.

[25] S. Lawn. Top tips for embedding chronic condition self-management support into practice. Aust J Prim Health 2010; 16: p. 334-343.

[26] Health and Social Care Information Centre. National Diabetes Audit 2012-2013, Report 1: Care processes and treatment targets. Findings about the quality of care for people with diabetes in England and Wales. (2014).

[27] L. Wenzel, for The Kings Fund. Informal and flexible appraoches to diabetes education: Report commissioned by Diabetes UK. (2016)

[28] G. Horigan, M. Davies, F. Findlay White, D. Chaney, V. Coates. Reasons why patients referred to diabetes education programmes choose not to attend: a systematic review. Diabetic Med 34 (2016) 4-26.

[29] D. White, N. Waugh, J. Elliott, J. Lawton, K. Barnard, M.J. Campbell, et al. The relative effectiveness of pumps over MDI and structured education (REPOSE):study protocol for a cluster randomised controlled trial. BMJ Open (2014) e006204.

[30] K. Pal, S.V. Eastwood, S. Michie, A.J. Farmer, M.L. Barnard, R. Peacock, et al. Computerbased diabetes self-management interventions for adults with type 2 diabetesmellitus. Cochrane Database Syst Rev. 3 (2013) CD008776.

[31] Tsapas A, Matthews DR. $\mathrm{N}$ of 1 trials in diabetes: making individual therapeutic decision. Diabetologia. 51 (2008) 921-925.

[32] D.T. O'Keeffe, V.M. Montori. What's up \#DOC? The role of social media in diabetes management. Diabetic Med 33 (2016) 853-854. 